\title{
Trote universitário: diversão ou constrangimento entre acadêmicos da saúde?
}

Simone de Melo Costa ${ }^{1}$, Orlene Veloso Dias ${ }^{2}$, André Costa Alencar Dias ${ }^{3}$, Thaynara Rocha de Souza ${ }^{4}$, João dos Reis Canela ${ }^{5}$

\section{Resumo}

O estudo objetivou identificar, entre universitários, a opinião acerca da participação no trote de calouros, bem como os possíveis constrangimentos relacionados. Participaram 202 estudantes com idade média de 20 anos, que correspondem a $80,8 \%$ dos universitários da instituição. A maioria $(77,5 \%)$ não vê o trote como violência e $67,8 \%$ dele participaram ao ingressar no curso. Entre os que percebem o trote como violência, não houve diferença entre sexo e o curso $(p>0,05)$. No entanto, a opinião prevalente daqueles com maior idade $(p<0,05)$, que não participaram do trote $(p<0,05)$, considera-o constrangedor $(p<0,05)$. Se grande parte dos estudantes avaliou positivamente o trote, mas os não participantes sentiram-se constrangidos, pode-se questionar em que medida as instituições de ensino superior podem continuar admitindo o trote como rito de passagem ou até que ponto se deve classificá-lo como processo opressivo, apesar de naturalizado.

Palavras-chave: Estudantes de ciências da saúde. Violência. Comportamento de massa. Comportamento social.

\section{Resumen}

\section{Rito de iniciación universitario: diversión o avergonzamiento entre académicos de la salud?}

El objetivo del estudio fue identificar entre los académicos, la opinión acerca de la participación en una novatada de estudiantes de primer año y las posibles consternaciones relacionadas. Acudieron 202 estudiantes con un promedio de edad de 20 años, lo que corresponde al $80,8 \%$ de los estudiantes de la institución. La mayoría $(77,5 \%)$ no ve a las novatadas como una violencia y el $67,8 \%$ participaron al ingresar al curso. Entre aquellos que perciben al rito como violencia, no hubo diferencia entre el sexo y el curso $(p>0,05)$. Sin embargo, la opinión predominante entre los mayores $(p<0,05)$, los que no participaron en las novatadas $(p<0,05)$, lo consideran vergonzoso $(p<0,05)$. Si la mayoría de los alumnos evaluaron positivamente el rito, pero, los que no s participaron se sintieron avergonzados, cabe preguntarse hasta qué punto las instituciones de educación superior pueden seguir admitiendo novatadas como un rito de pasaje o en qué medida se debe clasificarlo como proceso opresivo, aunque naturalizado.

Palabras-clave: Estudiantes de Ciencias de la Salud. Violencia. Conducta de masa. El comportamiento social.

\begin{abstract}
University hazing: amusement or embarrassment among academic health?

The study aimed to identify among academics the opinion about participation in freshmen hazing and possible constraints related. Two hundred and two students with a mean age of 20 years participated, which corresponds to $80.8 \%$ of the students of the institution. The majority $(77.5 \%)$ does not see hazing as embarrassment and $67.8 \%$ has participated on it to join the course. Among those who perceive hazing as violence, there was no difference between gender and course ( $p>.05)$. If most of the students evaluated positively the hazing, even feeling constrained about it, one might question the extent to which higher education institutions can continue admitting hazing as a rite of passage or to what extent it should sort it process as oppressive, though naturalized.
\end{abstract}

Key words: Students, health occupations. Violence. Mass behavior. Social behavior.

\section{Aprovação CEP Unimontes $n^{\circ}$ 2.669/2011}

1. Doutora smelocosta@gmail.com 2. Mestre orlenedias@yahoo.com.br 3. Graduando andreh2004@hotmail.com 4. Graduanda thaynararocha2009@gmail.com 5. Especialista jreis.canela@gmail.com - Universidade Estadual de Montes Claros (Unimontes), Montes Claros/MG, Brasil.

\section{Correspondência}

Simone de Melo Costa - Rua Dr. Walmor de Paula, 27, Vila Regina CEP 39400-198. Montes Claros/MG, Brasil. 
A sociedade se transformou e os níveis de violência e tolerância das pessoas também mudaram ${ }^{1}$. Nessa perspectiva, a violência dos trotes universitários passa a ser um dos problemas do sistema educacional a ser enfrentado.

No sentido de enfrentamento à violência dos trotes universitários no Brasil, a Câmara de Deputados aprovou, em 2009, o Projeto de Lei 1.023, que dispõe sobre a tipificação como contravenção penal, nos casos em que especifica a prática de trote estudantil. Essa lei, que criminaliza o trote violento, ainda não foi aprovada no Senado. Um de seus artigos determina a proibição da realização do trote que ofenda a integridade física, moral ou psicológica dos novos alunos; importe constrangimento a estes; os exponha, de forma vexatória, e implique pedido de doação de bens ou dinheiro a eles, salvo quando destinados à entidade de assistência social ${ }^{2}$.

O modelo socioecológico pressupõe que os comportamentos de agressão sejam formados por diferentes contextos interrelacionados, incluindo características individuais, familiares, de colegas e do ambiente escolar. Portanto, o problema é melhor entendido no contexto social em que ocorre, que pode contribuir para o envolvimento em situações de violência. Nessa perspectiva, destacam-se: professores que ignoram a violência, escolas com clima negativo e o perfil de estudantes que socializam com amigos a característica de valentão ${ }^{3}$.

Os estudantes universitários representam o grupo de pessoas frequentemente expostas a situações que envolvem violência ${ }^{4}$. No entanto, o alto índice de violência entre os universitários não culminou em discussão científica suficiente sobre como produzir mensagens antiviolência mais eficazes ${ }^{4}$ no âmbito das universidades. Ao considerar o trote como uma relação de poder, favorecidos (alunos em curso) contra desfavorecidos (alunos ingressantes), a temática passa a compor a discussão bioética por envolver conflitos éticos entre as pessoas.

A bioética do século XXI deve considerar as transformações com as quais convive a humanidade. Deve ser orientada pelo respeito e incentivo à liberdade do indivíduo na tomada de decisão, em adição aos outros princípios, como a solidariedade, na necessidade de proteger os mais desfavorecidos. Assim, espera-se uma bioética que contribua na busca de soluções para as tensões entre as liberdades individuais e os interesses coletivos, com ponderação e equilíbrio para as decisões razoáveis e prudentes ${ }^{5}$. Nesse sentido, o trote universitário gera conflitos éticos pelo potencial constrangimento que poderá causar aos sujeitos envolvidos, princi- palmente naqueles em situação de vulnerabilidade, na relação interpessoal acadêmica.

O objetivo deste estudo foi identificar entre os acadêmicos de saúde da Universidade Estadual de Montes Claros (Unimontes) a opinião acerca da participação no trote universitário e situações de constrangimento relacionadas ao mesmo.

\section{Material e método}

Trata-se de estudo de abordagem quantitativa e de cunho transversal. Os participantes da pesquisa foram os acadêmicos matriculados no primeiro ano dos cursos de graduação em Enfermagem, Odontologia, Medicina, Educação Física e Biologia, vinculados ao Centro de Ciências Biológicas e da Saúde (CCBS) da Unimontes, no ano de 2012. A pesquisa foi aprovada pelo Comitê de Ética em Pesquisa da Universidade Estadual de Montes Claros em respeito à Resolução 196/96 ${ }^{6}$, que trata das diretrizes e normas regulamentadoras sobre pesquisa envolvendo seres humanos.

O recorte com estudantes de graduação do primeiro ano do curso deveu-se ao fato de representar o ano que envolve a participação no trote universitário. Acadêmicos do primeiro período participam do trote como ingressantes à universidade e os matriculados no segundo período participam como organizadores, aplicando-o aos ingressantes. Cabe ressaltar que cada período representa um semestre acadêmico. No caso, os períodos $1^{\circ}$ e $2^{\circ}$ compõem o $1^{\circ}$ ano da graduação. Em paralelo, cada período é composto por 25 estudantes; sendo assim, a expectativa de participação foi de 50 acadêmicos em cada curso, perfazendo um universo de estudo de 250 participantes.

Para a coleta de dados, utilizou-se um questionário semiestruturado e autoaplicado contemplando questões relacionadas ao trote universitário. A coleta de dados ocorreu nas salas de aula, após um estudo piloto com a participação de 10 acadêmicos, que objetivou adequar o instrumento de coleta de dados.

Os dados coletados foram submetidos ao tratamento estatístico pelo programa Statistical Package for the Social Sciences (SPSS), versão 18.0. A análise estatística utilizou o cálculo de proporções, além de análises bivariadas, teste $\mathrm{t}$ (student) e Pearson qui-quadrado, considerando o nível de significância $p<0,05^{7}$. 


\section{Resultados}

Participaram do estudo 202 acadêmicos, que correspondem a $80,8 \%$ do total de estudantes dos $1^{\circ}$ e $2^{\circ}$ períodos inscritos nos diferentes cursos de saúde vinculados à Unimontes. Os estudantes apresentaram média de idade igual a 20,13 $( \pm 3,358)$, sendo a idade mínima 17 anos e a máxima, 37. A moda foi igual a 18 anos, a mediana 19 anos e o percentil $75 \%$ foi igual a 21 anos. A idade foi categorizada em 17 a 20 anos e maiores de 21 anos, sendo a menor faixa etária a mais predominante $(71,7 \%)$ entre os estudantes. A maior participação no estudo foi de mulheres $(67,8 \%)$ e de graduandos do $2^{\circ}$ período $(62,9 \%)$. Apenas $2 \%$ afirmaram não ter nenhum amigo na universidade. A distribuição dos universitários quanto ao curso ficou assim estabelecida: Biologia (20,8\%), Educação Física (17,8\%), Enfermagem $(22,8 \%)$, Odontologia $(21,3 \%)$ e Medicina $(17,3 \%)$.

Para grande parte dos estudantes $(77,5 \%)$, o trote universitário não caracteriza situação de cons- trangimento, ou seja, de violência. A participação no trote universitário, ao ingressar no curso, foi destacada pela maioria $(67,8 \%)$ dos estudantes. Para $69,7 \%$ dos acadêmicos, a participação no trote da Unimontes não provocou situações de constrangimento (Tabela 1).

Foi constatado que um pouco mais da metade $(55,9 \%)$ dos acadêmicos matriculados no $2^{\circ}$ período da graduação não participou da organização do trote universitário aplicado aos alunos ingressos no $1^{\circ}$ período. Dentre os 71 estudantes do $2^{\circ}$ período, $87,3 \%$ afirmaram não ter colocado os ingressantes em situações de constrangimento. Entre os motivos argumentados pelos acadêmicos para a aplicação do trote aos ingressantes, pode-se citar o fato de o considerarem como oportunidade de repetir com os novatos o mesmo tratamento que receberam ao ingressar na universidade, como se fosse um "troco". Contudo, as motivações mais destacadas para a organização do trote foram a diversão e interação entre os universitários (Tabela 1).

Tabela 1. Distribuição dos entrevistados conforme variáveis relacionadas ao trote universitário. Estudantes do primeiro ano da graduação, 2012

\begin{tabular}{|c|c|c|c|}
\hline Período & Variáveis & Frequência absoluta & Frequência relativa \\
\hline \multirow{12}{*}{$\begin{array}{l}\text { Estudantes do } 1^{\circ} \\
\text { e } 2^{\circ} \text { períodos }\end{array}$} & Trote é violência? $(\mathrm{N}=200)$ & $\mathrm{N}$ & $\%$ \\
\hline & Sim & 45 & $22,5 \%$ \\
\hline & Não & 155 & $77,5 \%$ \\
\hline & $\begin{array}{c}\text { Participou do trote ao ingressar na } \\
\text { universidade? }(\mathrm{N}=202)\end{array}$ & & \\
\hline & Sim & 137 & $67,8 \%$ \\
\hline & Não & 65 & $32,2 \%$ \\
\hline & $\mathrm{O}$ trote foi constrangedor? $(\mathrm{N}=137)$ & & \\
\hline & Sim & 41 & $30,3 \%$ \\
\hline & Não & 96 & $69,7 \%$ \\
\hline & $\begin{array}{l}\text { A não participação no trote ao ingressar } \\
\text { na universidade foi constrangedora? } \\
\text { (N=65) }\end{array}$ & & \\
\hline & Sim & 9 & $14,6 \%$ \\
\hline & Não & 56 & $85,4 \%$ \\
\hline \multirow{8}{*}{$\begin{array}{l}\text { Estudantes do } 2^{\circ} \\
\text { período }\end{array}$} & Aplicou trote aos ingressantes? $(\mathrm{N}=127)$ & & \\
\hline & Sim & 56 & $44,1 \%$ \\
\hline & Não & 71 & $55,9 \%$ \\
\hline & $\begin{array}{l}\text { Colocou os ingressantes em situação de } \\
\text { constrangimento? }(\mathrm{N}=56)\end{array}$ & & \\
\hline & Sim & 7 & $12,7 \%$ \\
\hline & Não & 49 & $87,3 \%$ \\
\hline & $\begin{array}{l}\text { O que o levou a aplicar o trote aos } \\
\text { ingressantes? }(\mathrm{N}=35)\end{array}$ & & \\
\hline & $\begin{array}{c}\text { Troco } \\
\text { Diversão/interação }\end{array}$ & $\begin{array}{c}6 \\
29\end{array}$ & $\begin{array}{l}17,1 \% \\
82,9 \%\end{array}$ \\
\hline
\end{tabular}


A opinião do acadêmico acerca do trote universitário ser violência foi associada às variáveis sexo, número de amigos, idade e curso de graduação em saúde. Constatou-se que respostas associando trote ao processo de violência foram maiores entre as mulheres $(p>0,05)$; entre aqueles que relataram não ter amigos na universidade $(p>0,05)$; entre os com idade superior e igual a 21 anos $(p<0,05)$ e entre os estudantes do curso de medicina $(p>0,05)$.

As médias de idade dos universitários foram comparadas conforme variáveis relacionadas ao tro- te dos cursos de saúde. Os que afirmaram ser o trote uma forma de violência apresentaram maior média de idade $(20,9 \pm 3,85)$ quando comparados aos com opinião contrária $(19,9 \pm 3,18)$, sendo a diferença não significativa $(p>0,05)$. As pessoas com maior média de idade não participaram do trote ao ingressar na universidade $(p<0,05)$, mas consideraram que a não participação os levou a situações de constrangimento $(p<0,05)$. Os estudantes mais velhos não participaram do trote aplicado aos ingressantes na universidade $(p<0,05)$ (Tabela 2$)$.

Tabela 2. Médias de idade e desvio padrão conforme variáveis relacionadas ao trote universitário. Estudantes de saúde da Unimontes, Montes Claros, MG, Brasil, 2012

\begin{tabular}{|c|c|c|c|}
\hline Período & Variáveis & $\begin{array}{l}\text { Média de idade } \\
\text { ( } \pm \text { desvio padrão) }\end{array}$ & $\mathbf{P}$ \\
\hline \multirow{12}{*}{$\begin{array}{l}\text { Estudantes do } 1^{\circ} \\
\text { e } 2^{\circ} \text { períodos }\end{array}$} & Trote é violência? & & \\
\hline & Sim & $20,9( \pm 3,85)$ & \multirow{2}{*}{0,086} \\
\hline & Não & $19,9( \pm 3,18)$ & \\
\hline & $\begin{array}{c}\text { Participou do trote ao ingressar na } \\
\text { universidade? }\end{array}$ & & \\
\hline & Sim & $19,8( \pm 2,81)$ & \multirow{2}{*}{0,036} \\
\hline & Não & $20,9( \pm 4,22)$ & \\
\hline & O trote foi constrangedor? & & \\
\hline & Sim & $19,8( \pm 1,95)$ & \multirow[b]{2}{*}{0,945} \\
\hline & Não & $19,8( \pm 3,04)$ & \\
\hline & $\begin{array}{c}\text { A não participação no trote ao } \\
\text { ingressar na universidade foi } \\
\text { constrangedora? }\end{array}$ & & \\
\hline & Sim & $22,4( \pm 4,57)$ & \\
\hline & Não & $20,1( \pm 3,86)$ & 0,000 \\
\hline \multirow{8}{*}{$\begin{array}{l}\text { Estudantes do } 2^{\circ} \\
\text { período }\end{array}$} & Aplicou trote aos ingressantes? & & \\
\hline & Sim & $19,3( \pm 1,80)$ & \multirow{2}{*}{0,005} \\
\hline & Não & $21,2( \pm 4,60)$ & \\
\hline & $\begin{array}{c}\text { Colocou os colegas ingressantes em } \\
\text { constrangimento? }\end{array}$ & & \\
\hline & Sim & $20,0( \pm 1,82)$ & \multirow{2}{*}{0,435} \\
\hline & Não & $19,3( \pm 2,39)$ & \\
\hline & $\begin{array}{c}\text { O que o levou a aplicar o trote aos } \\
\text { ingressantes? }\end{array}$ & & \\
\hline & $\begin{array}{c}\text { Troco } \\
\text { Diversão/interação }\end{array}$ & $\begin{array}{l}19,3( \pm 2,07) \\
20,6( \pm 4,19)\end{array}$ & 0,477 \\
\hline
\end{tabular}

Foi verificada a associação da variável "aplicação do trote quando veterano aos ingressantes universitários" conforme o sexo, número de amigos, idade e curso dos estudantes matriculados no $2^{\circ}$ período da graduação. Constatou-se que a idade entre 17 e 20 anos foi associada à condição de ter aplicado o trote aos ingressantes na universidade $(p<0,05)$. As pessoas do sexo masculino, sem amigos na universidade e estudantes do curso de Odontologia, apresentaram maior percentual de participantes; no entanto, todas as variáveis não apresentaram associação significativa $(p>0,05)$ (Tabela 3$)$. 
Tabela 3. Associação da aplicação do trote aos ingressantes universitários conforme sexo, número de amigos, idade e curso. Estudantes do $2^{\circ}$ período de graduação. 2012

\begin{tabular}{|c|c|c|c|}
\hline \multirow{2}{*}{ Variáveis } & \multicolumn{2}{|c|}{ Aplicou trote aos novatos? } & \multirow{2}{*}{$\mathrm{p}$} \\
\hline & $\operatorname{sim}(\%)$ & Não (\%) & \\
\hline \multicolumn{4}{|l|}{ Sexo } \\
\hline Masculino & $48,8 \%$ & $51,2 \%$ & \multirow{2}{*}{$p=0,496$} \\
\hline Feminino & $42,4 \%$ & $57,6 \%$ & \\
\hline \multicolumn{4}{|l|}{ Número de amigos } \\
\hline 0 & $50,0 \%$ & $50,0 \%$ & \multirow[b]{2}{*}{$p=1,000$} \\
\hline$\geq 1$ & $44,0 \%$ & $56,0 \%$ & \\
\hline \multicolumn{4}{|l|}{ Idade } \\
\hline $17-20$ anos & $51,8 \%$ & $48,2 \%$ & \multirow{2}{*}{$p=0,042$} \\
\hline$\geq 21$ anos & $31,4 \%$ & $68,6 \%$ & \\
\hline \multicolumn{4}{|l|}{ Curso } \\
\hline Biologia & $26,7 \%$ & $73,3 \%$ & \multirow{5}{*}{$p=0,090$} \\
\hline Educação Física & $42,9 \%$ & $57,1 \%$ & \\
\hline Enfermagem & $40,0 \%$ & $60,0 \%$ & \\
\hline Odontologia & $61,5 \%$ & $38,5 \%$ & \\
\hline Medicina & $55,6 \%$ & $44,4 \%$ & \\
\hline
\end{tabular}

\section{Discussão}

A média de idade dos estudantes foi compatível para a classificação de adulto jovem, igual a 20,13, que corresponde à idade de ingresso na universidade. A pesquisa avaliou apenas os acadêmicos matriculados no primeiro ano de graduação de diferentes cursos de formação em saúde. Verificou-se que $25 \%$ dos estudantes apresentaram idade compreendida entre 17 e 18 anos, considerados adolescentes conforme o Estatuto da Criança e do Adolescente (ECA), instituído no Brasil em 1990 - que considera essa fase como a compreendida entre 12 e 18 anos $^{8}$.

Os estudantes universitários com idades entre 18 e 24 anos correspondem ao grupo mais frequentemente exposto a situações que envolvem diferentes tipos de violência. Têm maior acesso ao consumo de álcool e drogas e, ao mesmo tempo, são menos supervisionados pelos pais, quando comparados aos grupos etários mais jovens. A participação frequente em eventos violentos pode prejudicar seriamente os estudantes universitários, tanto fisica como psicologicamente ${ }^{4}$.

O trote da Unimontes não se caracteriza como situação de constrangimento na opinião da maioria dos estudantes, que afirmou ter participado ao ingressar na universidade. Esse resultado vai ao encontro da literatura. A aparente tolerância social em relação ao trote tem razão teórica forte por ser pensado como rito de passagem entre a adolescência e a vida adulta, cujas origens podem ser consideradas uma "tradição", vez que remontam à própria criação das universidades no período medieval ${ }^{9}$.

Não se pode desconsiderar o percentual de acadêmicos que consideraram a participação no trote constrangedora, bem como o percentual de não participantes que caracterizam a não participação também constrangedora. Sendo assim, participar ou não participar pode levar a constrangimento. É importante considerar, ainda, a menor participação, neste estudo, de estudantes ingressantes na universidade. Fato que pode ser explicado pelo receio de responder às questões vinculadas ao trote universitário, haja vista que a experiência do trote foi vivenciada no mesmo período da coleta de dados, o que poderia estar indicando um desconforto tão acentuado que não pode nem mesmo ser mencionado, dado o temor da possibilidade de haver represálias.

A maioria dos estudantes que participaram do estudo é do sexo feminino, o que vai ao encontro da 
feminização da saúde. Esse fato foi constatado em pesquisa na mesma universidade, no curso de graduação em Odontologia ${ }^{10}$. A opinião que considera o trote uma violência foi destacada pelas mulheres, pelos que relataram não ter amigos na universidade, os com idade superior e igual a 21 anos e dentre os estudantes do curso de Medicina, sendo a associação estatisticamente significativa apenas para a variável idade. Estudo etnográfico com acadêmicos de Medicina de universidade pública do Estado de São Paulo constatou nas falas dos graduandos que o trote universitário caracteriza-se como meio de violência, medo e submissão dos sujeitos, em escala de poder hierarquizado na instituição ${ }^{11}$.

A idade foi fator importante na questão do trote universitário, pois se detectou que a maioria dos estudantes do $2^{\circ}$ período, principalmente aqueles com maior média de idade, não aplicou o trote nos novatos. Neste contexto, a maior idade pode ter representado, em parte, maturidade para a não adesão ao trote universitário aplicado aos novos acadêmicos, apesar dos que apresentaram maior média de idade se sentirem constrangidos na condição de não participantes no trote ao ingressar na universidade. Pode-se conjecturar em que medida esse constrangimento não decorra das sensações de distanciamento e inadequação em relação à maioria, que podem dificultar o relacionamento entre os discentes.

Entretanto, a maioria dos que aplicaram o trote afirmou não ter colocado os alunos novos em situações de constrangimento. A sensação de "troco" foi uma das motivações para a participação no trote aplicado aos ingressantes, e a diversão e interação foram os motivos mais destacados pelos acadêmicos do $2^{\circ}$ período. 0 "troco" deve ser analisado com cuidado, pois se caracteriza como perpetuar a violência, ideia que na atualidade começa a ser socialmente bem aceita. Talvez por isso tenha se constatado o maior percentual de respostas caracterizando o trote como "diversão", já que, para muitos, "divertir" pode não implicar em provocar constrangimento ao colega. Cabe considerar que tal argumento pode muitas vezes não ser verdade para os que se encontram em desvantagem - no caso do trote, os calouros.

Quanto ao trote universitário, no futuro próximo o oprimido se torna opressor, chega sua vez de humilhar o outro como foi humilhado, e o ciclo perpetua-se. Aquele submetido ao trote não mostra resistência efetiva, para não ser considerado diferente pelo grupo ${ }^{12}$.

Em outro estudo, estudantes universitários se consideraram vítimas durante o trote. Ao avaliar os trotes divulgados na mídia foram constatados casos de espancamentos e até mortes durante o momento de pintar e cortar cabelo, atos aparentemente seguros, mas que oportunizam atitudes mais violentas. $O$ trote, apesar de tradição que acontece há décadas, não pode continuar sendo tolerado. É preciso que o sistema de ensino superior se mobilize para combater esta tradição. Além do mais, o uso indevido de palavras como "calouro" e "veterano" envolve o sentido de hierarquia, que pode gerar abusos. Trote é exclusão e não integração entre os acadêmicos ${ }^{13}$.

De modo persistente, o trote causa danos aos estudantes que ingressam nas universidades. $O$ trote se refere a uma situação cultural, na qual abusar do outro é transformado em algo engraçado. $O$ outro passa a ser objeto de diversão, de chacota, de ridicularização, de violência. Essa situação cultural propicia a expressão livre dos desequilíbrios individuais ${ }^{14}$.

O trote universitário pode ser comparado a outros tipos de ridicularização da violência. Por exemplo, as "pegadinhas" televisivas nas quais as pessoas são expostas a situações de vexame e até de risco. A filmografia de violência e os videogames violentos também são parte de uma cultura de banalização da violência interpessoal. Tal cultura em nossa sociedade se estende da violência verbal, por meio da desclassificação da pessoa, da chacota e da ridicularização de sexo biológico, a atributos físicos, cor, orientação sexual, entre outros. Até a violência física pode manifestar-se em diferentes comportamentos, tais como embebedar os participantes, jogar tinta, ovos ou outros materiais com cor, textura ou cheiro desagradável, uso de venda para impedir a visão, mordaça, imobilização por corda ou fita adesiva, empurrões, chutes, tapas e socos, além de provas de submersão em água suja e até mesmo lama.

Cabe também lembrar que desde sua instituição, há mais de 700 anos, o trote vem provocando a morte de calouros em diferentes instituições e regiões de todo o mundo ${ }^{9}$. Estudo conduzido com estudantes universitários americanos detectou que o trote é prática generalizada e envolve uma série de organizações estudantis e equipes esportivas. 0 consumo de álcool, humilhação, isolamento, privação de sono e atos sexuais são comuns em trotes a grupos de estudantes ${ }^{15}$.

No Brasil, pesquisa constatou que os excessos cometidos durante o trote universitário são percebidos por professores e graduandos como situações normais, que incluem brigas abusivas entre calouros e veteranos. As dificuldades, conflitos, desacertos e agressões são individuais, e as respostas às agres- 
sões idem, por ser uma violência consentida, naturalizada e esperada. Uma possível explicação para essa naturalização da violência do trote é a ausência de reflexão sobre o tema, o sentimento de impotência, por um lado, e a negação, por outro ${ }^{16}$.

Contudo, os danos causados pelo trote não se restringem às suas vítimas, mas também aos agressores, pois estudantes aprendem a beber e a usar outras drogas, a humilhar, a manter um clima de atrito com os colegas. Os estudantes naturalizam as hierarquias e se tornam menos preocupados com o comportamento ético. Enquanto o trote ocorre como algo banalizado pelas pessoas, os pesquisadores da educação superior pouco se preocupam com a abordagem do tema. O trote é importante assunto a ser debatido, pois sem esse debate continuará a formar opressores para um sistema produtivo opressor a ser naturalizado pelas pessoas ${ }^{14}$.

Em estudo realizado com graduandos americanos, verificou-se que a exposição à campanha de marketing social aumentou a consciência do papel de cada um na redução da violência de relacionamento e perseguição, bem como a vontade expressa de envolvimento ${ }^{15}$. Assim, a universidade poderá ter um papel importante, projetando mensagens de prevenção da violência e destacando as normas de comportamento a serem exploradas e adotadas no contexto universitário.

Em pesquisa exploratória realizada junto aos coordenadores de cursos de Medicina e Enfermagem em universidades públicas e privadas, nos estados brasileiros do Rio de Janeiro e Cuiabá, constatou-se o reconhecimento da violência como um problema de saúde. Os entrevistados sugeriram a inserção do tema violência na graduação, indicando a urgência de renovação na estrutura do currículo dos cursos de formação em saúde ${ }^{16}$. Contudo, com relação à violência no trote, as medidas teriam que ser implantadas já no primeiro ano de graduação, para atingir o contingente populacional que participa e que aplica o trote universitário, acadêmicos ingressantes e os matriculados no $2^{\circ}$ período.

Apesar de instituída em 1948, a Declaração Universal de Direitos Humanos ainda não é respeitada em sua integridade, especialmente em relação à afirmação do direito de autodeterminação, do respeito ao princípio da autonomia do sujeito, do direito de agir livremente conforme sua consciência e valores morais ${ }^{17}$. Isso remete à necessidade da discussão bioética em prol do respeito ao cidadão, de maneira ampla na sociedade, incluindo a universidade e as relações entre estudantes para prevenir atitudes de maus tratos e abusos com os colegas.
Sabe-se que essa tarefa não é fácil: discutir a aplicação de princípios éticos em uma sociedade capitalista na qual as pessoas estão preocupadas em satisfazer os desejos e interesses individuais em detrimento à reflexão sobre os aspectos relacionados ao bem coletivo. Nos cursos de formação em saúde é especialmente necessário desenvolver a consciência crítica acerca das forças sociais maléficas para a vida e a saúde dos indivíduos da coletividade. Em adição, os acadêmicos devem reconhecer os seus papéis de cidadãos que se posicionam contra todo tipo de violência ${ }^{18}$.

Em termos bioéticos, a reflexão sobre o trote relacionada ao curso de saúde pode ser associada aos conceitos, virtudes ou aos princípios bioéticos que permitam discutir os possíveis benefícios e malefícios tanto da prática quanto da supressão do trote.

Ao considerar o trote como rito de passagem, cabe questionar os valores que caracterizam a nova fase do desenvolvimento acadêmico. O que se espera dos graduandos em saúde é se importar com o outro e não agredi-lo como uma violência naturalizada, em que algumas pessoas ficam vulneráveis ou em situação de submissão a um grupo dominante ${ }^{16}$. Manter a prática do trote violento traz malefícios para a comunidade acadêmica ao projetar nos estudantes de saúde os valores de dominação nas relações interpessoais. Esta possibilidade de constranger acadêmicos nos trotes violentos suscita a discussão bioética em busca de soluções equilibradas.

Deve-se considerar que o chamado trote universitário pode ser transformado em uma prática saudável, de interação e diversão entre os acadêmicos, em ação que provoque a solidariedade entre os participantes, que proteja os menos favorecidos e que respeite a liberdade dos sujeitos na tomada de decisões.

Nessa perspectiva, a Declaração Universal sobre Bioética e Direitos Humanos expressa princípios que poderiam nortear uma prática de trote saudável. Entre eles, pode-se destacar o respeito às liberdades fundamentais, a não discriminação e estigmatização em qualquer circunstância e o princípio de solidariedade entre indivíduos que estão em situações histórico-sociais diferentes, sendo que uns devam apoiar os outros, de modo desinteressado de retorno material ou de qualquer outra natureza ${ }^{19}$. Os princípios devem confrontar as ações do trote universitário, que na maioria dos casos se prestam a explorar e tirar vantagens daqueles que recém chegaram à universidade e que nesta situação são os que mais necessitam amparo e acolhimento. 
Apesar dos esforços empreendidos na discussão dos resultados deste estudo, cabe enfatizar a dificuldade encontrada devido à escassez de publicações envolvendo a temática do trote universitário. Quanto às limitações do estudo, tem-se o fato de ter sido conduzido em uma única instituição de ensino superior, escolhida por se tratar de instituição de vínculo dos pesquisadores. Porém, a avaliação foi de cunho censitário para estudantes matriculados no $1^{\circ}$ ano dos cursos de graduação em saúde.

\section{Considerações finais}

A maturidade, representada neste estudo pela maior idade dos estudantes, foi importante fator associado para a não participação do trote nem ao ingressar na universidade nem na condição de estudante com curso em andamento. Em adição, para os que aplicaram o trote aos ingressantes, a maior idade foi associada à autoavaliação de percepção de ter colocado os colegas em situação de constrangimento. Apesar de a maioria dos estudantes ter afirmado que participou do trote ao ingressar no curso e não o ter considerado constrangedor, não se pode desconsiderar as pessoas que ficaram constrangidas tanto na participação como na não participação do trote universitário.

Contudo, o trote universitário passa a ser problema quando se pensa na constituição de pessoas autônomas e no fim dos processos opressivos da sociedade. 0 tema precisa ser mais bem discutido no sentido de romper a continuidade dessas práticas de violência naturalizada nas instituições de ensino superior. Isto é um desafio a ser enfrentado, considerando que o trote foi associado aos mais jovens, que o percebem como diversão e interação entre os estudantes, desconsiderando o constrangimento causado aos outros.

A interface entre o trote universitário, a reflexão bioética e a formação em saúde indica a contradição que se acentua no trote violento na área da saúde, ou seja, entre um ritual que reproduz a violência e contradiz com a prática profissional futura do estudante voltada à atenção e ao cuidado em saúde. Desse modo, o trote violento, caracterizado como ritual de passagem, nega a própria essência da formação do acadêmico de saúde, tendo um papel nefasto no início da relação ensino-aprendizagem. Os reflexos bioéticos desta ótica são evidentes pela vulnerabilidade de acadêmicos ingressantes e responsabilidades, tanto individual como coletiva, que deveriam permear os acadêmicos em estágios mais avançados da graduação. Por fim, o que se espera dos futuros profissionais de saúde é o acolhimento como estratégia de boas-vindas aos ingressantes na instituição de ensino superior.

Sugerem-se mais publicações cientificas sobre a temática do trote universitário, para que possam ser utilizadas como material didático em sala de aula junto aos jovens universitários, no sentido de contribuir tanto para a reflexão ética em torno do assunto quanto para o seu enfrentamento, com vistas a aprofundar a reflexão e a consciência sobre o assunto, reduzindo, consequentemente, a vitimização de indivíduos.

Agradecemos à Universidade Estadual de Montes Claros (Unimontes) pelo incentivo à iniciação científica aos acadêmicos coautores deste estudo. Edital Programa Institucional de Iniciação Científica - Proinic 2011 (ICV/Unimontes).

\section{Referências}

1. Almeida Jr OR, Queda O. Bullying escolar, trote universitário e assédio moral no trabalho: uma investigação sobre similaridades e diferenças. Antitrote. [Internet]. 2011 [acesso 25 mar. 2012]. Disponível: http://www.antitrote.org/artigos/?id=26

2. Brasil. Câmara dos Deputados. Projeto de Lei $n^{\circ} 1.023 / 1995$. Dispõe sobre as atividades de recepção aos novos alunos nas instituições de ensino. Autor: deputado Feu Rosa. Câmara dos Deputados. [Internet]. 8 set. 1995 [acesso 25 mar. 2012]. Disponível: http://www.antitrote.org/ artigos/?id=29

3. Espelage DL, De La Rue L. School bullying: its nature and ecology. Int J Adolesc Med Health. 2011;24(1):3-10.

4. Yu HJ. Producing more persuasive antiviolence messages for college students: testing the effects of framing, information sources, and positive/negative fact appeal. J Interpers Violence. 2012;27(9):1631-54.

5. Fortes PAC. A bioética em um mundo em transformação. Rev. bioét (Impr.). 2011;19(2):319-27.

6. Conselho Nacional de Saúde (Brasil). Diretrizes e normas regulamentadoras sobre pesquisa envolvendo seres humanos. Resolução n 196, de 10 de outubro de 1996. Brasília: Ministério da Saúde; 1996. 
7. Pestana MH, Gageiro JN. Análise de dados para ciências sociais: complementaridade do SPSS. $3^{\text {a }}$ ed. Lisboa: Edições Silabo; 2003.

8. Brasil. Lei $n^{\circ} 8.069$, de 13 de julho de 1990. Dispõe sobre o Estatuto da Criança e do Adolescente e dá outras providências. Brasília: Presidência da República; 1990.

9. Zuin AAS. O trote na universidade: passagens de um rito de iniciação. São Paulo: Cortez; 2002.

10. Costa SM, Durães SJA, Abreu MHNG. Feminização do curso de odontologia da Universidade Estadual de Montes Claros. Ciênc Saúde Coletiva. [Internet]. 2012 [acesso 18 dez. 2012];15(Supl. 1):1873-2010. Disponível: http://www.scielo.br/pdf/csc/v15s1/100.pdf

11. Almeida MT. A ordem médica e a desordem do sujeito na formação profissional médica. Rev bioét (Impr.). 2011;19(3):741-52.

12. Siqueira VHF, Fonseca MCG, Sá MB, Lima ACM. Construções identitárias de estudantes de farmácia no trote universitário: questões de gênero e sexualidade. Pro-Posições [Internet]. 2012 [acesso 6 jun. 2013];23(2):145-59. Disponível: http://www.scielo.br/pdf/pp/v23n2/a10v23n2. pdf

13. Dearo G. Trote é exclusão, não integração. [Internet]. 17 fev. 2011 [acesso 25 mar. 2012]. Disponível:http://guiadoestudante.abril.com.br/vestibular-enem/trote-exclusao-naointegracao-diz-professor-usp-619019.shtml

14. Almeida Jr OR. Uma forma institucional de glorificar a violência. [Internet]. 2011 [acesso 25 mar. 2012]. Disponivel: http://www.antitrote.org/artigos/?id=27

15. Allan EJ, Madden M. The nature and extent of college student hazing. Int J Adolesc Med Health. 2012;24(1):83-90.

16. Villaca FM, Palacios M. Concepções sobre assédio moral: bullying e trote em uma escola médica. Rev Bras Educ Med. [Internet]. 2010 [acesso 6 jun. 2013];34(4):506-14. Disponível: http://www. scielo.br/pdf/rbem/v34n4/v34n4a05.pdf

17. United Nations. The Universal Declaration of Human Rights. [Internet]. Adopted and proclaimed by Resolution $217 \mathrm{~A}(\mathrm{III})$ of the UN General Assembly on December 10, 1948 [acesso $18 \mathrm{dec}$. 2012]. Disponível: http://www.un.org/en/documents/udhr/

18. Souza ER, Ribeiro AP, Penna LHC, Ferreira AL, Santos NC, Tavares CMM. O tema violência intrafamiliar na concepção dos formadores dos profissionais de saúde. Ciênc Saúde Coletiva. 2009 [acesso $1^{\circ}$ out. 2012];14(5). Disponível: http://www.scielo.br/pdf/csc/v14n5/12.pdf

19. Organização das Nações Unidas para a Educação, a Ciência e a Cultura (Unesco). Declaração Universal sobre Bioética e Direitos Humanos. [Internet]. Paris: Unesco; 1997 [acesso 17 jun. 2009]. Disponível: http://unesdoc.unesco.org/images/0014/001461/146180por.pdf

\section{Participação dos autores}

Simone de Melo Costa, Orlene Veloso Dias, André Costa Alencar Dias, Thaynara Rocha de Souza e João dos Reis Canela participaram igualmente de todas as etapas de elaboração do artigo.

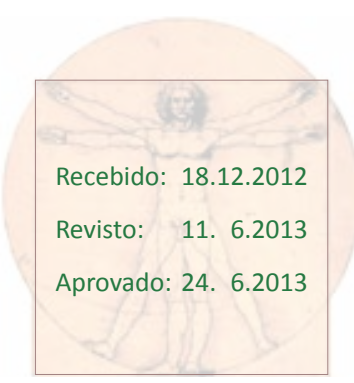

